\title{
FLOW INDUCED VIBRATION IN SQUARE CYLINDER OF VARIOUS ANGLES OF ATTACK
}

\author{
Nur Ain Shafiza Ramzi ${ }^{1}$, Lee Kee QueN ${ }^{1 *}$, Nur Amira BalqiS Mohd \\ ZAINURI ${ }^{1}$, HOOI-SIANG KANG ${ }^{2,3}$, NOR'AZIZI OTHMAN ${ }^{1}$ \\ AND KENG YINN WONG ${ }^{2}$ \\ ${ }^{I}$ Mechanical Precision Engineering, Malaysia-Japan International Institute of Technology, \\ Universiti Teknologi Malaysia, Kuala Lumpur, Malaysia \\ ${ }^{2}$ School of Mechanical Engineering, Faculty of Engineering, \\ Universiti Teknologi Malaysia, Malaysia \\ ${ }^{3}$ Marine Technology Center, Institute for Vehicle System and Engineering, \\ Universiti Teknologi Malaysia, Malaysia \\ *Corresponding author: Ikquen@utm.my
}

(Received: 22 ${ }^{\text {nd }}$ January 2021; Accepted: $24^{\text {th }}$ May 2021; Published on-line: $4^{\text {th }}$ January 2022)

\begin{abstract}
An experimental study was carried out to identify the effect of angle of attack on flow-induced vibration (FIV) of square cylinders. The experiment was conducted at the Aeronautical and Wind Engineering Laboratory (AEROLAB), UTM Kuala Lumpur using a wind tunnel that was free from external wind conditions. A supporting structure was designed and fabricated to conduct this experiment. The importance of this support structure was to enable the rigid cylinder to suspend and vibrate freely upon excitation of wind speed. The results were analysed through the response of amplitude and frequency of the rigid cylinder over a velocity range of $0.5 \mathrm{~m} / \mathrm{s}$ to $4.0 \mathrm{~m} / \mathrm{s}$. The results showed that for a square cylinder of $\alpha=0^{\circ}$, vortex-induced vibration (VIV) occurred at low reduced velocity $\left(U_{R}\right)$ in range of $5 \leq U_{R} \leq 10$ and galloping occurred at higher reduced velocity which started at $U_{R}=15$. A tranquil zone was found between VIV and galloping in the reduced velocity range of $10 \leq U_{R} \leq 15$. As for $\alpha=22.5^{\circ}$ and $45^{\circ}$, only VIV response was found at low reduced velocity in range of $4 \leq U_{R} \leq 9$.
\end{abstract}

ABSTRAK: Satu kajian eksperimentasi telah dilakukan bagi mengenal pasti pengaruh sudut serangan oleh getaran cetusan-aliran (FIV) dalam silinder persegi. Eksperimen ini dijalankan di Makmal Kejuruteraan Aeronautika dan Angin (AEROLAB), UTM Kuala Lumpur dengan menggunakan terowong angin yang bebas dari pengaruh angin luar. Struktur sokongan telah direka dan difabrikasi bagi tujuan eksperimen ini. Ini penting bagi membolehkan silinder pegun tergantung dan bergetar dengan bebas semasa ujian kelajuan angin. Dapatan kajian dianalisis melalui tindak balas amplitud dan frekuensi silinder pegun pada kadar halaju $0.5 \mathrm{~m} / \mathrm{s}$ sehingga $4.0 \mathrm{~m} / \mathrm{s}$. Hasil kajian menunjukkan bahawa bagi silinder persegi $\alpha=0^{\circ}$, getaran pengaruh-vorteks (VIV) berlaku pada halaju rendah $\left(U_{R}\right)$ dalam julat $5 \leq U_{R} \leq 10$ dan getaran lebih teruk telah ketara berlaku pada kadar halaju berkurang iaitu bermula pada $U_{R}=15$. Zon tenang dijumpai antara VIV dan getaran teruk pada kadar halaju berkurang $10 \leq U_{R} \leq 15$. Adapun pada $\alpha=22.5^{\circ}$ dan $45^{\circ}$, hanya tindak balas VIV dijumpai pada halaju rendah dalam kadar $4 \leq U_{R} \leq 9$.

KEYWORDS: flow-induced vibration; square cylinder; galloping; angle of attack; tranquil zone 


\section{INTRODUCTION}

Flow-induced vibration (FIV) of a bluff body has received huge attention in various fields such as the aerospace industry, bridges, tall buildings, smokestacks, power generation, and engineering infrastructure. Therefore, FIV has been a hot topic for researchers for the past 20 years and various methods have been undertaken such as experiments and simulations to investigate FIV on cylindrical structures [1-2]. VIV and galloping can be categorized under FIV phenomenon, where VIV occurs at steady conditions while galloping can be considered as unsteady FIV phenomenon that usually arises in asymmetrical bodies. Previous study has reported that galloping usually occurs at high flow speeds [3-10]. Failures or problems that may occur from FIV are usually due to improper design. Therefore, understanding on the characteristic of flow induced vibration is of utmost importance because of its physical applications and the possibility of causing severe damage if improper design is applied. The collapse of the Tacoma Narrows Bridge in 1940 was a well-known accident that was caused by FIV. Due to its catastrophic effects, continuous research on FIV is highly demanded to provide a better understanding of its characteristics in order to avoid such accidents from happening again.

In civil engineering, consideration of wind path over buildings and other rectangular structures is particularly vital as it leads to variation in the structure's angle of attack. Angle of attack can be described as the angle between the reference line of the body and the relative oncoming motion flow such as air and water. The angle of attack may result in uneven pressure distributions that can lead to unpredictable loading patterns. Based on the previous research, study on the effect of angle of attack is very limited.

Nemes et al. [11] is one of the few teams that have investigated the interaction between flow-induced vibration mechanisms of a square cylinder with different angles of attack. The experiment was conducted in a free surface recirculating water channel and reported that VIV and galloping occurred over a narrow range of angles of incidence. Hu et al. [12] conducted an experiment with various angles from $0^{\circ}$ to $\pm 30^{\circ}$ and found that as the forward inclination increased, the crosswind responses of the cylinder decreased, while for the backward inclination, the crosswind response did not reduce evenly. On the other hand, Kawai, [13] conducted an experiment in a boundary wind tunnel with three types of flow (smooth flow, turbulent boundary layer flow over open terrain, and turbulent boundary layer flow over urban area). From the results, strong VIV was noticed at angles of attack of $0^{\circ}$ and $15^{\circ}$. When the angle of attack exceeded $15^{\circ}$, VIV became weak and could not be detected in the smooth flow. As for turbulent boundary layer flow over urban area, the weak VIV was still seen for angles of attack greater than $15^{\circ}$. Galloping was also found in this experiment when the angle of attack was $0^{\circ}$ with reduced velocity equal to 10 . Zhao et al. [14] studied FIV on a square cylinder with two angles of incidence of $0^{\circ}$ and $45^{\circ}$. The results showed that galloping occurred at $0^{\circ}$ while VIV occurred at $45^{\circ}$. In the literature review, some conflicts of the outputs are found. For example, Obasaju et al. [15] found a tranquil zone between VIV and galloping for $\alpha=0^{\circ}$, but Nemes et al. [11] reported no tranquil zone in their study. Other studies did not show relative outputs on this issue [16-20]. Hence, this gains our interest for further investigation of the issue. The main purpose of the present study is to identify the characteristic of the FIV around a square cylinder based on various angles of attack, at the same time clarifying whether the galloping occurs right after VIV or there is a resting gap without the occurrence of galloping and VIV. 


\section{METHODOLOGY}

\subsection{Experimental Details}

The experiments were conducted in the AF100 subsonic wind tunnel of the Aeronautical and Wind Engineering Lab (AEROLAB) in the University Technology Malaysia, Kuala Lumpur, as shown in Fig. 1. The test section size was $33 \mathrm{~cm}$ in width, 35 $\mathrm{cm}$ in height, and $70 \mathrm{~cm}$ in length. The main objective of this experiment was to identify the effect of different angles of attack towards the FIV of a rigid cylinder with one degree of freedom (1dof). By using three different angles of attack, the behavior of FIV could be observed.

A clear acrylic was used as the material for the square cylinder. Acrylic was chosen because the material is lightweight. The cylinder was attached on the supporting structure using circular acrylic plate with a diameter of $6 \mathrm{~cm}$. Fig. 2 shows the schematic diagram of the angle of attack for the rigid square cylinder.

To analyse the effect of angle of attack, three angles, namely $0^{\circ}, 22.5^{\circ}$, and $45^{\circ}$, were tested in the present study. The reason for using these angles is that they correspond to the conditions where the reactions are dominated by VIV and galloping [21]. Table 1 shows the specification of the cylinders.

In order to attach the coiled spring, holes were made at the end of each circular plate. The function of the coiled spring was to suspend the cylinder on the supporting structure. The coiled springs were attached in parallel for both sides. Using laser cutting, 6 holes were made at the circular plate to allow the rigid cylinders to hang in the pre-set angles. The steel supporting structure was made with the dimensions of $29 \mathrm{~cm} \times 29 \mathrm{~cm} \times 29 \mathrm{~cm}$ in length, width, and depth, respectively. For the coiled spring, low stiffness was used in the experiment to generate the lock-in condition. The dimensions, the set-up of the rig, and schematic diagram of the experiment are shown in Fig. 3(a), 3(b), and 3(c), respectively.

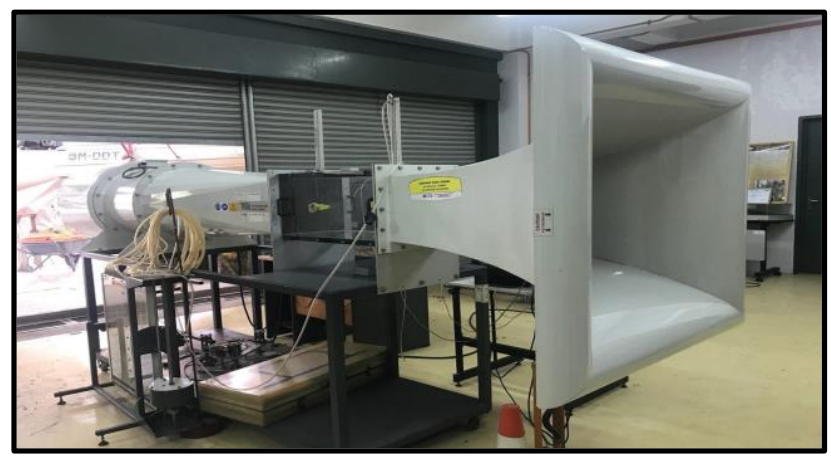

Fig. 1: The overview of AF100 Subsonic Wind Tunnel.

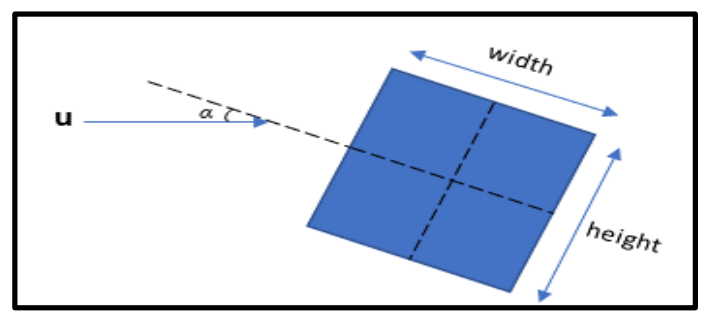

Fig. 2: The angle of attack of a square rigid cylinder. 
Table 1: Specification of the cylinder

\begin{tabular}{lll} 
Overview & Dimension $(\mathbf{c m})$ & Weight $(\mathbf{g})$ \\
\hline & Aspect ratio $=1$ & \\
Width $=3.0$ & \\
& Height $=3.0$ & \\
& Length $=17.5$ \\
\end{tabular}

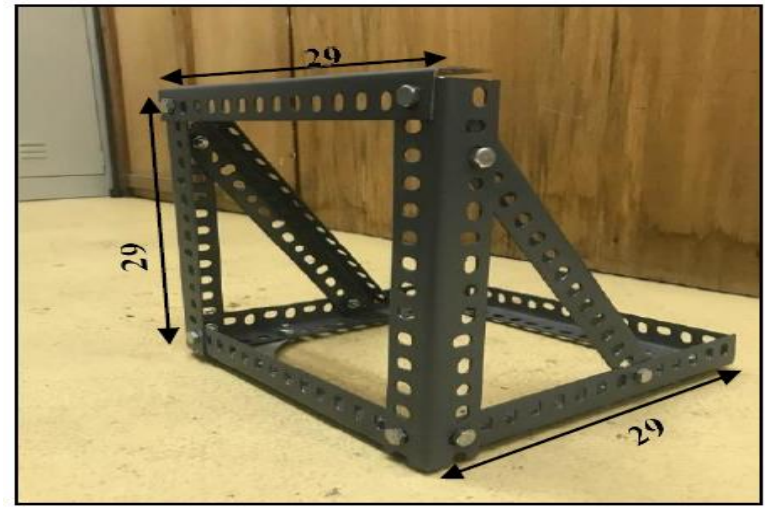

(a)

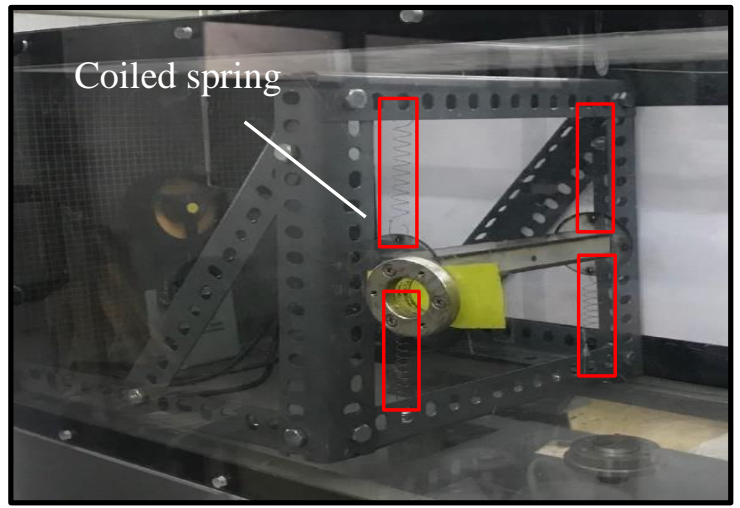

(b)

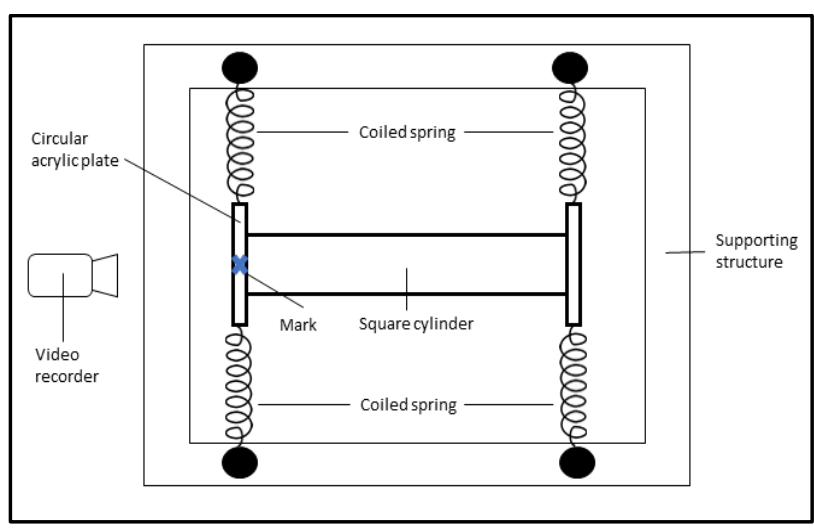

(c)

Fig. 3: (a) The dimensions of the rig. (b) the set-up of the rig and (c) schematic diagram of the experiment.

\subsection{Measuring Equipment}

To record all the data obtained from the experiment, it was important to use proper measuring equipment. The equipment used must be sensitive to the vibration test in order to find the dynamic responses of the rigid cylinders. The equipment that was used to gain the results was the GES-28004 anemometer, pitot-static probe, video recorder, and laptop equipped with tracker video analysis and modelling tool software. The uniformity of the wind tunnel was checked using an anemometer and pitot tube as shown in Fig. 4 and Fig. 5, respectively. Anemometer was used to measure the air speed $(\mathrm{m} / \mathrm{s})$ in the wind tunnel while 
the pitot-static probe was used to measure the pressure $(\mathrm{Pa})$ of air in the wind tunnel. To record the vibration response of the cylinder, a video recorder was used. The video was converted into the amplitude of the vibration using the tracker video analysis modelling tool software, as shown in Fig. 6. In addition, in order to obtain the frequency response of the cylinder, the amplitude data needed to be converted from the time domain into the frequency domain using Fast Fourier Transform (FFT). An FFT Spectrum Analyzer implemented Fourier's basic theorem that denotes any waveform in the time domain by weighting the sum of pure sine waves of all frequencies. From the Discrete Fourier Transform, FFT is developed with the Eq. (1):

$$
A(r)=\sum_{k=0}^{N-1} X(s) e^{\frac{-j 2 \pi}{N^{r s}}}, r=0,2, \ldots, N
$$

In which, $X(s)$ is the periodic wake that is sampled at Nyquist frequency or higher and $S$ is the number of samples collected from original signals.

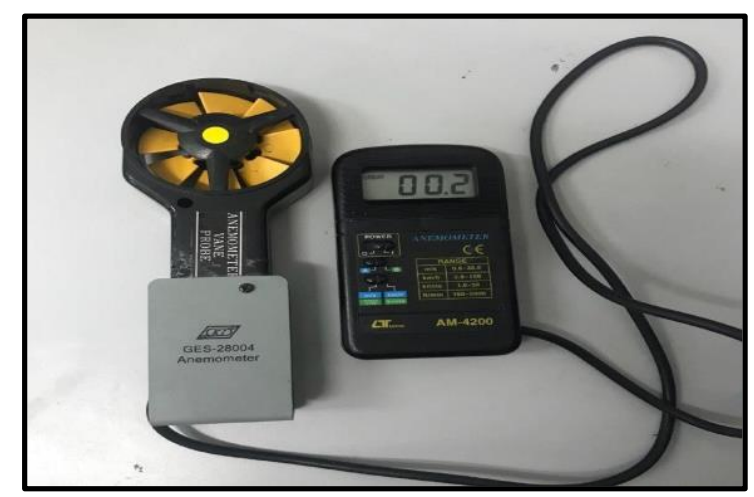

Fig. 4: Anemometer.

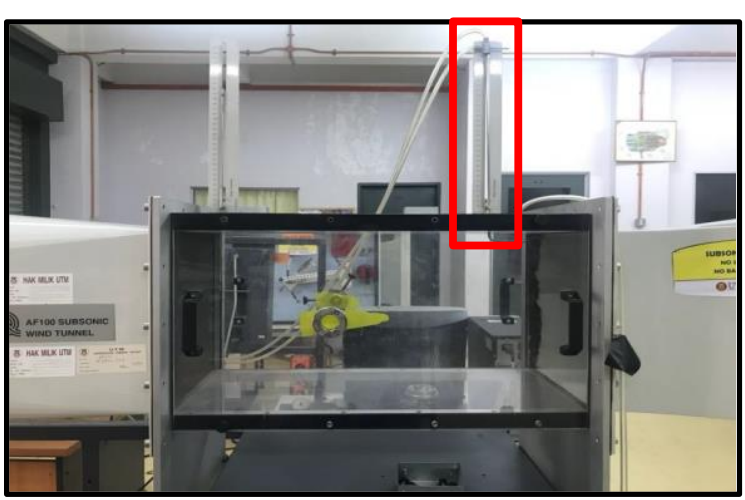

Fig. 5: Pitot-static probe.

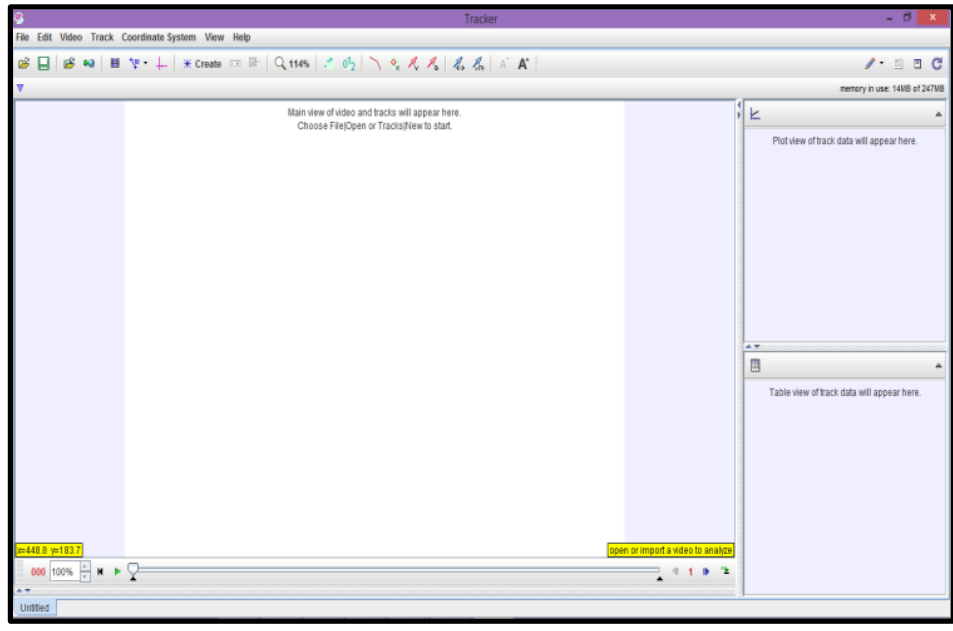

Fig. 6: Tracker video analysis and modelling tool software.

The supporting structure was placed inside the wind tunnel, while the video recorder was used to record the video of the vibration of the cylinder. The recorder was held by the tripod outside the wind tunnel. The experiments were over a range of velocities from 0.5 $\mathrm{m} / \mathrm{s}$ to $4.0 \mathrm{~m} / \mathrm{s}$, corresponding to the Reynolds number ranging from 16853 134831. The experiment was conducted with three different angles of attack on the square cylinder. The sampling frequency of the video recorder was $30 \mathrm{~Hz}$, which is adequate to collect the motion of the cylinder. The angle was changed in order to observe the dynamic responses at each 
angle of attack. The process of the experimental work can be summarized in the flow chart shown in Fig. 7.

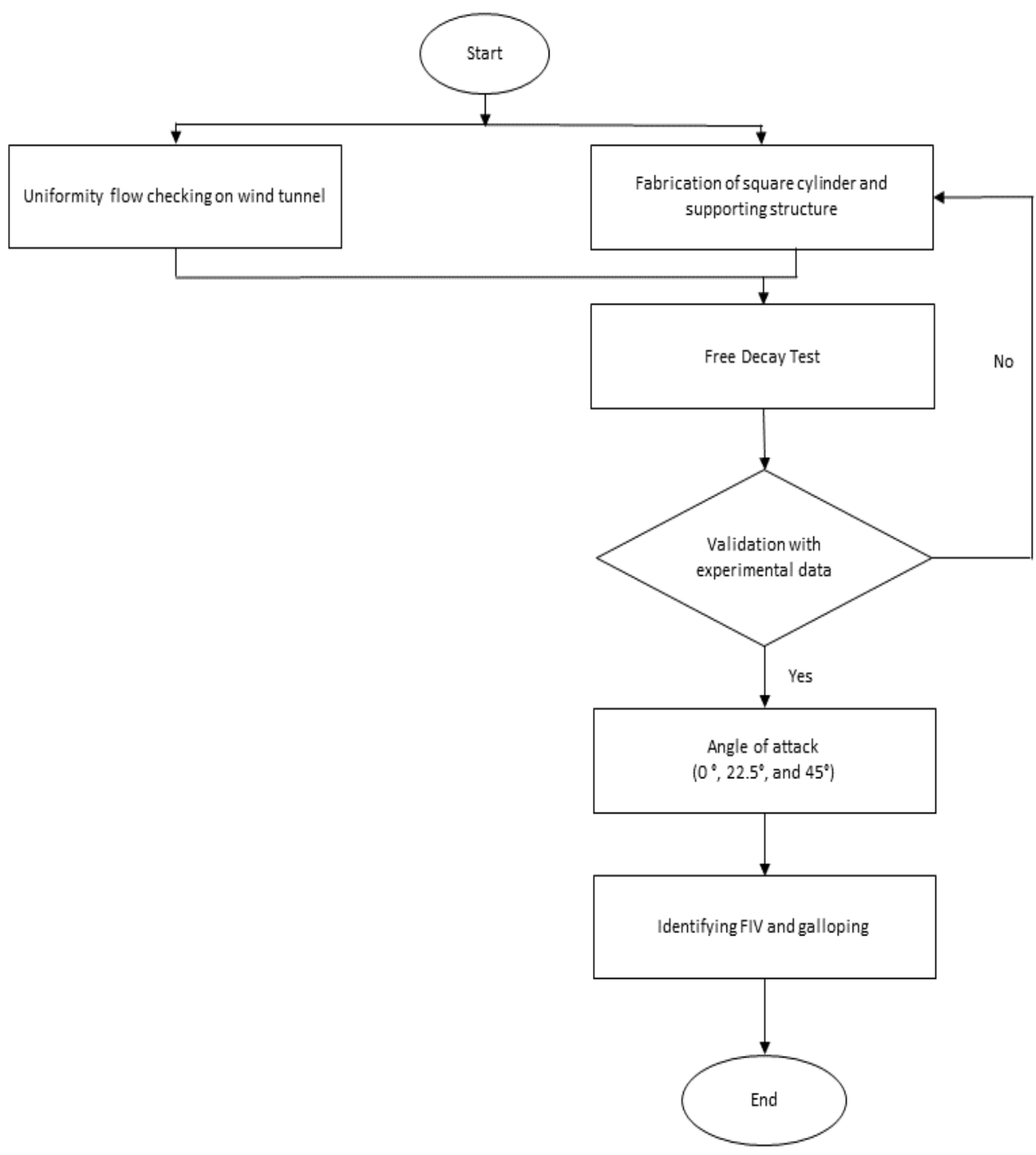

Fig. 7: The process of experimental work.

\section{RESULTS AND DISCUSSION}

\subsection{Uniformity of the Flow in Wind Tunnel}

Before conducting the experiments, the uniformity of the wind tunnel needed to be checked to ensure the flow was in a uniform condition. Three different velocities were observed, which is $9 \mathrm{~m} / \mathrm{s}, 6 \mathrm{~m} / \mathrm{s}$, and $3 \mathrm{~m} / \mathrm{s}$.

After obtaining the data, the uniformity of each velocity of the experiment was calculated using this Eq. (2) [22]:

$$
\Phi=\sqrt{\sum_{i=1}^{n} \frac{\left(\beta_{i}-\bar{\beta}\right)^{2}}{n}}
$$

where; $\beta_{i}=$ Measured value (velocity) $\bar{\beta}=$ Average value (average velocity) $n=$ Number of samples. From the calculations, the results for non-uniformity $(\Phi)$ are shown in Table 2. Based on the calculated results, all of the data shows small values, indicating low non- 
uniformity of the air flow. Hence, the flow uniformity in the wind tunnel was in good condition, and suitable for use to investigate the effect of FIV on the square cylinders.

Table 2: Non-uniformity at different speeds

\begin{tabular}{cc}
\hline Velocity $(\mathbf{m} / \mathbf{s})$ & $\Phi$ \\
\hline 3 & 0.149 \\
6 & 0.103 \\
9 & 0.063 \\
\hline
\end{tabular}

\subsection{Free Decay Test}

In this present study, the natural frequency value is important because as the value of the shedding frequency slowly reaches the natural frequency, the vibration of the rigid cylinder will increase to high values. To obtain the natural frequency, a free decay test was conducted by pulling the cylinder downward and allowing it to vibrate freely until it stopped. The natural frequency of the square cylinder was obtained from the power spectrum graph. To verify the experimental value of the natural frequency, the theoretical value of the natural frequency was calculated using Eq. (3):

$$
f_{n}=\frac{\sqrt{\frac{K_{\text {Total }}}{m_{\text {Total }}}}}{2 \pi}
$$

where $\mathrm{k}_{\text {Total }}$ is the stiffness of the system while $\mathrm{m}_{\text {Total }}$ is the mass of the system. This equation was adopted from previous study of VIV with similar experimental settings [23]. The value obtained for spring stiffness of the system was $119.6 \mathrm{~N} / \mathrm{m}$ as the springs were attached in parallel. Table 3 shows the value obtained from experiment and calculation. The percentage error is found to be $9.81 \%$. Similar error percentages were also reported in [23] where up to $11.55 \%$ of error percentage was achieved using the same equation. Since the error percentage was less than $20 \%$, the experimental value should be acceptable [24]. Hence, the design of the experimental rig was verified. Based on the free decay test, the damping ratio was found to be 0.008185 . Because the damping ratio was very low, the damping effect was unaccounted in the present study.

Table 3: The comparison between experimental and theoretical value of the natural frequency

\begin{tabular}{ccc}
\hline \multicolumn{2}{c}{ Natural frequency $(\mathbf{H z})$} & $\begin{array}{c}\text { Percentage } \\
\text { of error }(\boldsymbol{\%})\end{array}$ \\
\hline 6.783 & 6.177 & 9.81 \\
\hline
\end{tabular}

\subsection{Verification of the Experiment Data}

Strouhal number is a non-dimensional parameter that describes the oscillation of a cylinder. In the present study, the Strouhal number considering the VIV condition was found at 0.1257, as shown in Fig. 8(a) for $\alpha=0^{\circ}$. This was in agreement with Okajima [25], who suggested that the Strouhal number of alternating vortices shed from a square cylinder can be estimated to be about 0.13 in the Reynolds-number range between $10^{2}$ and $3.4 \times 10^{5}$. 


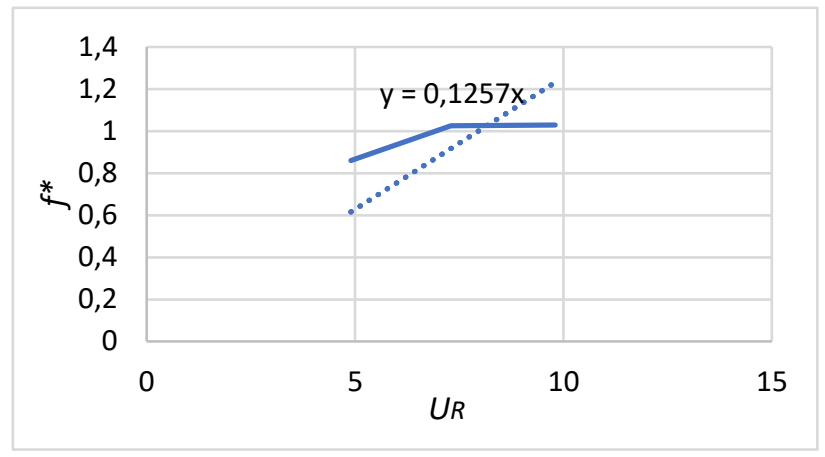

Fig. 8: Frequency ratio versus reduced velocity with angle of attack $\alpha=0^{\circ}$.

Maruai et al. [26] conducted a series of experimental measurements of flow-induced vibration using a square cylinder with a downstream flat plate. In their study, they stated that for an isolated square cylinder, only two significant flow-induced vibration behaviours can be observed, namely, VIV that occurs at lower branch velocity and galloping that occurs at higher branch velocity. To verify the data of the present study, the existing amplitude ratio of an isolated square cylinder [26] was compared with the square cylinder response of the present study, as shown in Fig. 9. The amplitude ratio was defined as $A *=y / d$ where y is the standard deviation of amplitude and $d$ is the cylinder height. A very similar trend was found with small deviation. The patterns of both studies were in good agreement. The occurrence of VIV in both studies was at a reduced velocity range of $5 \leq U_{R} \leq 11$ and galloping at $U_{R}>15$. The reduced velocity is defined as $U_{R}=\mathrm{U} / \mathrm{f}_{\mathrm{n}} \mathrm{d}$, where $U$ is free stream velocity, $f_{n}$ is the natural frequency and $\mathrm{d}$ is the cylinder height. However, the amplitude of the present study was slightly lower than the previous study because of the different damping ratio value. Based on Fig. 9, the current experimental work was verified.

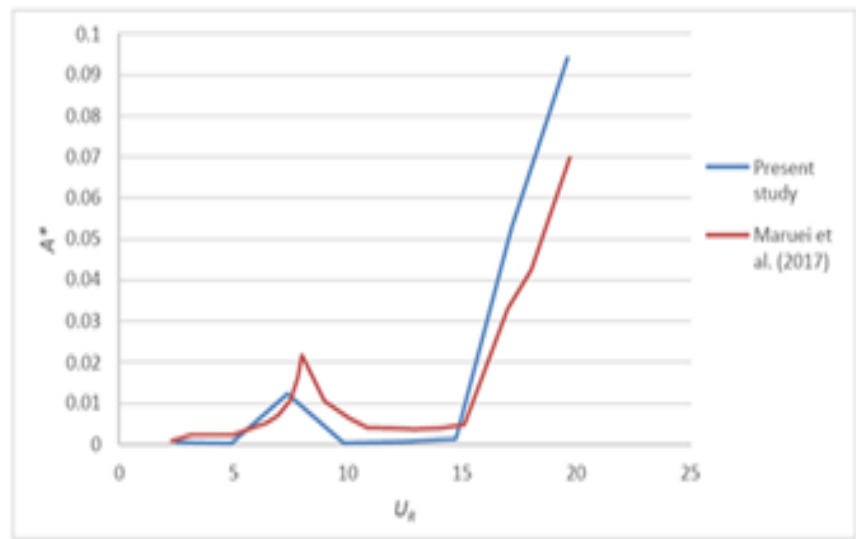

Fig. 9: Amplitude ratio versus reduced velocity of the previous study [26] and the present study.

\subsection{Effect of the Angle of Attack}

To investigate the effect of angle of attack on the FIV of the square cylinder, experiments were carried out over a wide range of reduced velocities at angles of attack of $\alpha=0^{\circ}, 22.5^{\circ}$, and $45^{\circ}$. Fig. 10 shows the comparison of the amplitude response of various angle of attacks. From the graph, it can be observed that galloping response was only found at $\alpha=0^{\circ}$ as the vibration amplitude of the cylinder increased with increasing reduced velocity 
at $U_{R}=15$. Other than that, VIV response was also observed at lower branch of reduced velocity in the range of $5 \leq U_{R} \leq 10$. On other hand, only VIV behavior was found for square cylinder of $\alpha=22.5^{\circ}$ and $45^{\circ}$ where galloping is absent. Nevertheless, the occurrence of VIV for both angle of attacks is at low reduced velocity range $4 \leq U_{R} \leq 9$, which was slightly earlier than the cylinder of $\alpha=0^{\circ}$. It was also observed that the amplitude of the cylinder at $\alpha=22.5^{\circ}$ was lower compared to the amplitude of cylinder at $\alpha=45^{\circ}$. Based on this finding, it can be concluded that the cylinder of $\alpha=22.5^{\circ}$ had less tendency towards the VIV response. In fact, Cui et al. [27] also has shown the similar results, where in their study, cylinder of $\alpha=22.5^{\circ}$ had lower VIV amplitude compared to the others. Next, a region free from VIV and galloping was found at reduced velocity in the range of $10 \leq U_{R} \leq 15$ for $\alpha=0^{\circ}$, which is in agreement with Maruai et al. [26]. Therefore, it can be said that for a square cylinder, a tranquil zone was found between the phenomena of VIV and galloping.

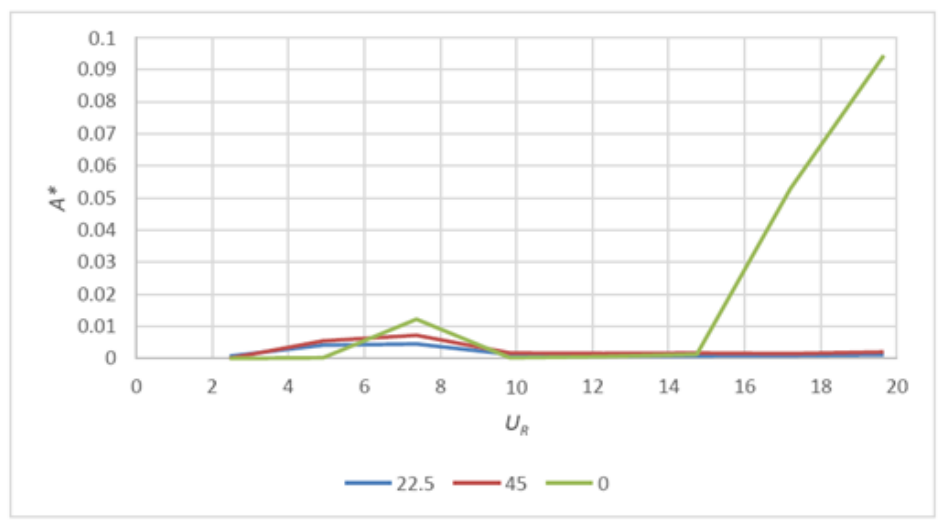

Fig. 10: Amplitude ratio of the rigid cylinder of various angles of attack.

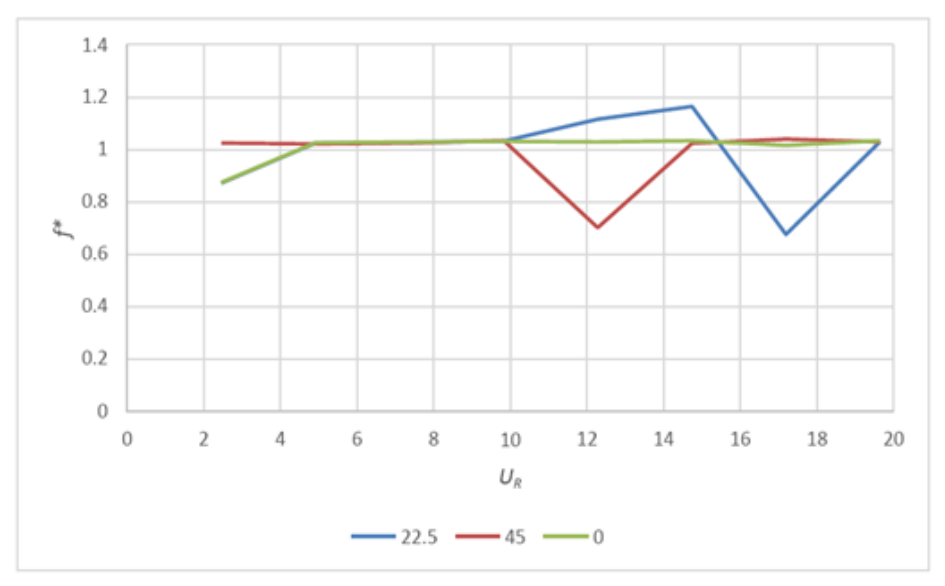

Fig. 11: Frequency ratio of the rigid cylinder of various angles of attack.

Fig. 11 shows the comparison of the frequency ratio of the different angles of attack where frequency ratio is defined as $f^{*}=f / f_{n}$, $\mathrm{f}$ is the vibrating frequency, and $f_{n}$ is the natural frequency of the cylinder. As shown in Fig. 11, the frequency ratio was close to 1 as the $U_{R}$ $>5$ for $\alpha=0^{\circ}$. This indicates that the cylinder underwent lock-in phenomena. Supposedly, the frequency ratio would be slightly higher or lower than 1 when galloping occurred at $U_{R}>15$. The same goes for the frequency ratio for $\alpha=22.5^{\circ}$ and $45^{\circ}$. The frequency ratio of the cylinder was supposedly higher than 1 when $U_{R}>10$ and increased monotonically with increasing reduced velocity to indicate that it was outside the lock-in regime and galloping did not occur [27]. However, in the present study, the described condition did not happen. Therefore, the power spectrum graph obtained from the FFT method were investigated in 
detail to identify the energies that were possessed by the cylinder at different angles of attack.

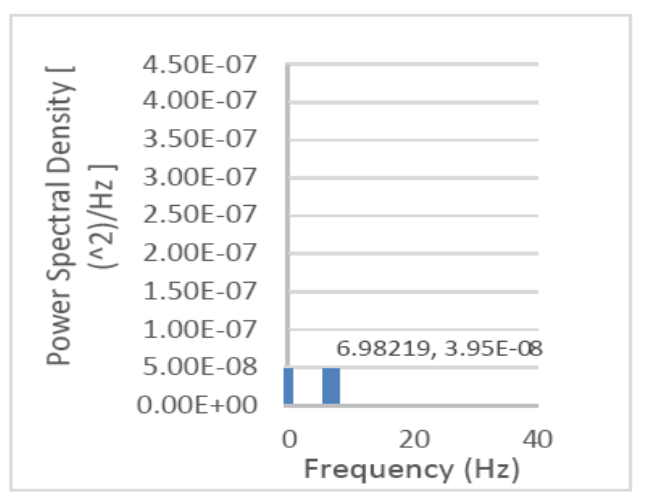

(a)

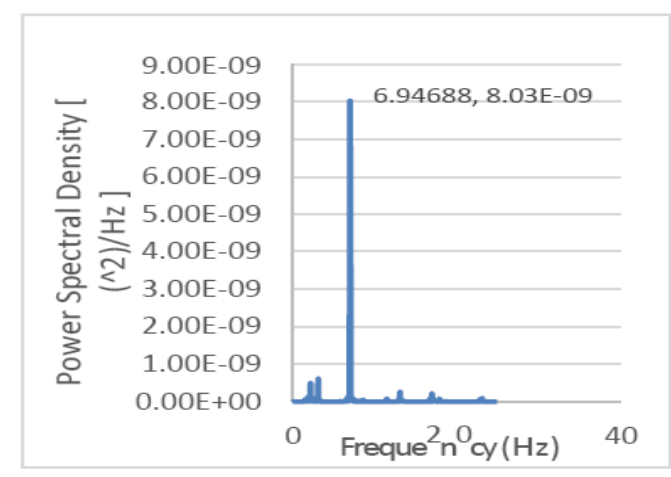

(c)

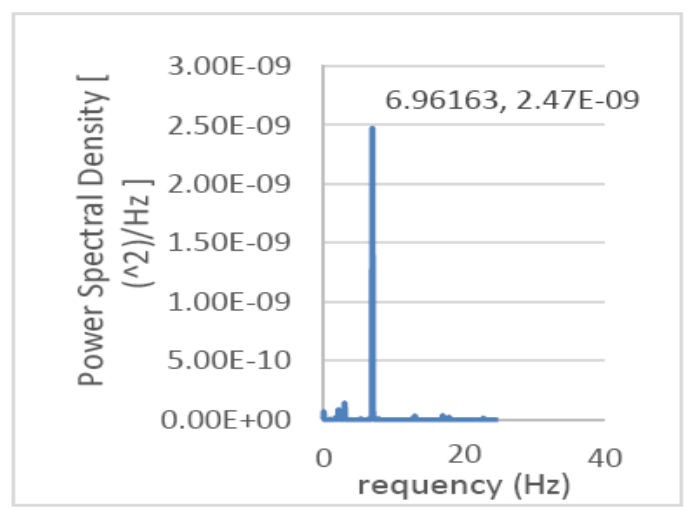

(e)

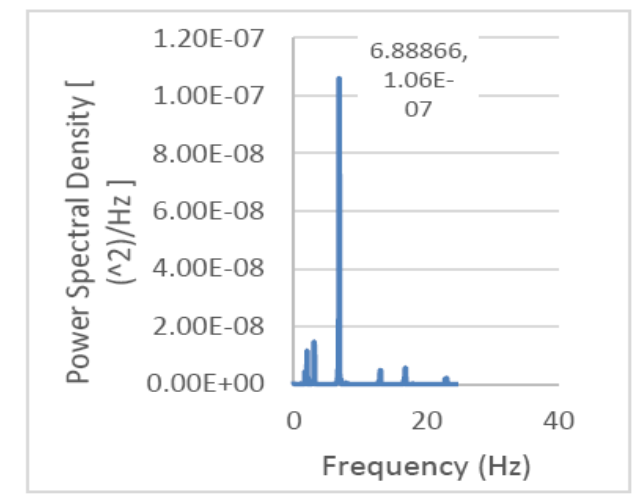

(b)

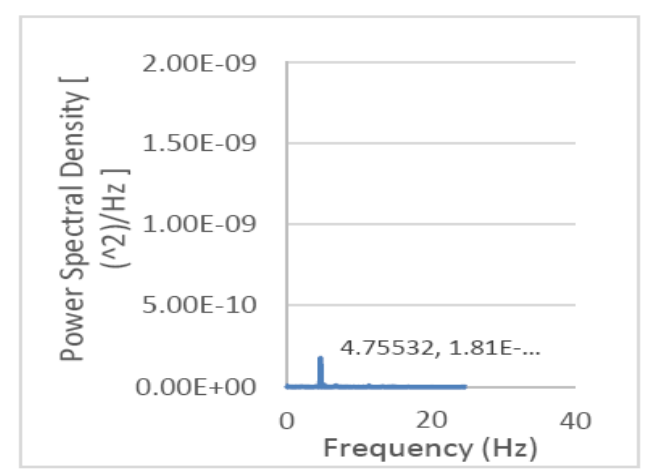

(d)

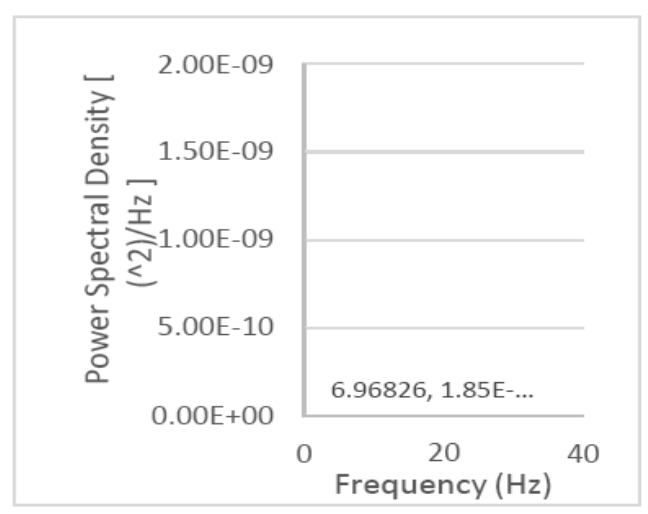

(f)

Fig. 12: (a) and (b): $U_{R}=7$ and 17 for $\alpha=0^{\circ}$; (c) and (d): $U_{R}=7$ and 17 for $\alpha=22.5^{\circ}$; (e) and (f): $U_{R}=7$ and 17 for $\alpha=45^{\circ}$.

Fig. 12(a) and (b) show the power spectrum graph of $\alpha=0^{\circ}$ when $U_{R}=7$ and $U_{R}=17$ respectively. For the case of $\alpha=0^{\circ}$, both VIV and galloping occurred. It was observed that the value of power spectrum density (PSD) at $U_{R}=7$ (where the lock-in condition occurred) was lower than the value of the power spectrum density at $U_{R}=17$ (where the galloping occurred). This condition can be justified as galloping possesses higher vibration energy than VIV. Fig. 12(c) and (d) show the power spectrum graph of $\alpha=22.5^{\circ}$ at $U_{R}=7$ and 17 respectively, while Fig. 12(e) and (f) show the power spectrum density of $\alpha=45^{\circ}$ at $U_{R}=7$ and 17 respectively. Based on Fig. 12(c-f), it can be seen that the value of power spectrum 
density at $U_{R}=17$ was lower than $U_{R}=7$. This is because there is no occurrence of galloping at $U_{R}=17$. In addition, Fig. 12(c) and Fig. 12(e) show a significant PSD peak during lockin condition $\left(U_{R}=7\right)$. On the contrary, multiple peaks with relatively small PSD values were found at $U_{R}=17$ (Fig. 12(d) and (f)). Hence, this justifies that although the frequency ratio remained close to 1 for $\alpha=22.5^{\circ}$ and $45^{\circ}$, no occurrence of galloping was found and the PSD values were small with multiple frequency peaks.

\section{ACKNOWLEDGEMENT}

This research was financially supported by Japan International Cooperation Agency (JICA) research grant (S.K130000.0543.4Y191) and Universiti Teknologi Malaysia research grant (Q.K130000.3043.03M14).

\section{REFERENCES}

[1] Bearman PW, Gartshore IS, Maull DJ, Parkinson GV. (1987) Experiments on flow-induced vibration of a square-section cylinder. Journal of Fluids and Structures, 1(1):19-34. doi:https://doi.org/10.1016/S0889-9746(87)90158-7

[2] A Rahman MA, Wan Hussin WN, Mohd MH, Noor Harun F, Quen LK, Paik JK. (2019) Modified wake oscillator model for vortex-induced motion prediction of low aspect ratio structures. Ships and Offshore Structures, 14(Sup1):1-9. doi:10.1080/17445302.2019.1593308

[3] Khalak A, Williamson CH. (1999) Motions, forces and mode transitions in vortex-induced vibrations at low mass-damping. Journal of fluids and Structures, 13(7-8):813-851. doi:https://doi.org/10.1006/jfls.1999.0236

[4] Bearman PW. (1984) Vortex shedding from oscillating bluff bodies. AnRFM, 16:195-222. doi:https://doi.org/10.1146/annurev.fl.16.010184.001211

[5] Sarpkaya T. (2004) A critical review of the intrinsic nature of vortex-induced vibrations. $\begin{array}{llll}\text { Journalof fluids and } & \text { 389-447. }\end{array}$ doi:https://doi.org/10.1016/j.jfluidstructs.2004.02.005

[6] Carberry J, Sheridan J, Rockwell D. (2005) Controlled oscillations of a cylinder: forces and wake modes. Journal of Fluid Mechanics, 538: 31-69. doi:https://doi.org/10.1017/S0022112005005197

[7] Govardhan RN, Williamson CHK. (2006) Defining the 'modified Griffin plot' in vortex-induced vibration: revealing the effect of Reynolds number using controlled damping. Journal of fluid mechanics, 561: 147-180. doi:https://doi.org/10.1017/S0022112006000310

[8] Ng YT, Luo SC, Chew YT. (2005) On using high-order polynomial curve fits in the quasisteady theory for square-cylinder galloping. Journal of fluids and structures, 20(1): 141-146. doi:https://doi.org/10.1016/j.jfluidstructs.2004.02.008

[9] Klamo JT, Leonard A, Roshko A. (2006) The effects of damping on the amplitude and frequency response of a freely vibrating cylinder in cross-flow. Journal of Fluids and Structures, 22(6-7): 845-856. doi:https://doi.org/10.1016/j.jfluidstructs.2006.04.009

[10] Shirakashi M, Chua CP, Salim SAZS. (2016) Design and fabrication of fiv apparatus for classroom lecture demonstration. Jurnal Teknologi, 78(9): 1-7. doi:https://doi.org/10.11113/jt.v78.4933

[11] Nemes A, Zhao J, Jacono DL, Sheridan J. (2012) The interaction between flow-induced vibration mechanisms of a square cylinder with varying angles of attack. doi:https://doi.org/10.1017/jfm.2012.353

[12] Hu G, Li C, Tse KT, Kwok KCS. (2018) Vortex induced vibration of an inclined finite-length square cylinder. European Journal of Mechanics-B/Fluids, 68:144-152. doi:https://doi.org/10.1016/j.euromechflu.2017.12.004

[13] Kawai H. (1995) Effects of angle of attack on vortex induced vibration and galloping of tall buildings in smooth and turbulent boundary layer flows. Journal of Wind Engineering and Industrial Aerodynamics, 54: 125-132. doi:https://doi.org/10.1016/0167-6105(94)00035-C 
[14] Zhou J, Nemes A, Jacono DL, Sheridan J. (2010) The effect of incidence angle variation of a square cylinder on its dynamic response and wake states. In Proceedings of the 17th Australasian Fluid Mechanics Conference, pp. 724-727). Auckland, New Zealand: AFMC

[15] Obasaju ED, Ermshaus R, Naudascher E. (1990) Vortex-induced streamwise oscillations of a square-section cylinder in a uniform stream. Journal of Fluid Mechanics, 213:171-189. doi:http://dx.doi.org/10.11113/jt.v79.9987

[16] Du X, Chen R, Dong H, Ma W, Xu H, Zhao Y. (2021) Aerodynamic characteristics of two closely spaced square cylinders in different arrangements. Journal of Wind Engineering and Industrial Aerodynamics, 208: 104462. doi: https://doi.org/10.1016/j.jweia.2020.104462

[17] Yanovych V, Duda D, Uruba V. (2021) Structure turbulent flow behind a square cylinder with an angle of incidence. European Journal of Mechanics-B/Fluids, 85: 110-123. doi: https://doi.org/10.1016/j.euromechflu.2020.09.003

[18] Cao Y, Tamura T. (2020) Low-frequency unsteadiness in the flow around a square cylinder with critical angle of $14^{\circ}$ at the Reynolds number of $2.2 \times 104$. Journal of Fluids and Structures, 97:103087. doi : https://doi.org/10.1016/j.jfluidstructs.2020.103087

[19] Peng S, Wang H, Zeng L, He X. (2019) Low-frequency dynamics of the flow around a finitelength square cylinder. Experimental Thermal and Fluid Science, 109: 109877. doi: https://doi.org/10.1016/j.expthermflusci.2019.109877

[20] Zhao J, Leontini J, Jacono DL, Sheridan J. (2019) The effect of mass ratio on the structural response of a freely vibrating square cylinder oriented at different angles of attack. Journal of Fluids and Structures, 86:200-212. doi: https://doi.org/10.1016/j.jfluidstructs.2019.02.008

[21] Zhao J, Leontini JS, Jacono DL, Sheridan J. (2014) Fluid-structure interaction of a square cylinder at different angles of attack. Journal of Fluid Mechanics, 747: 688-721. doi: https://doi.org/10.1017/jfm.2014.167

[22] Hassan JM, Mohamed TA, Mohammed WS, Alawee WH. (2014) Modeling the uniformity of manifold with various configurations. Journal of Fluids, 2014. https://doi.org/10.1155/2014/325259

[23] Shaharuddin NMR, Darus IM. (2015) Experimental study of vortex-induced vibrations of flexibly mounted cylinder in circulating water tunnel. Acta Mechanica, 226(11): 3795-3806. doi: https://doi.org/10.1007/s00707-015-1438-8

[24] Cecconi M, Rhodes A, Poloniecki J, Della Rocca G, Grounds RM. (2009) Bench-to-bedside review: the importance of the precision of the reference technique in method comparison studies-with specific reference to the measurement of cardiac output. Critical Care, 13(1):1-6. doi:https://doi.org/10.1186/cc7129

[25] Okajima A. (1982) Strouhal numbers of rectangular cylinders. Journal of Fluid Mechanics, 123: 379-398. doi: https://doi.org/10.1017/S0022112082003115

[26] Maruai NM, Mat Ali MS, Ismail MH, Shaikh Salim SAZ. (2017) Downstream flat plate as the flow-induced vibration enhancer for energy harvesting. Journal of Vibration and Control, 24(16): 3555-3568. doi:https://doi.org/10.1177/1077546317707877

[27] Cui Z, Zhao M, Teng B, Cheng L. (2015) Two-dimensional numerical study of vortex-induced vibration and galloping of square and rectangular cylinders in steady flow. Ocean Engineering, 106:189-206. doi:https://doi.org/10.1016/j.oceaneng.2015.07.004 